\title{
A Pobreza Rural e Urbana Brasileira sob a Ótica das Privações: Uma Análise Regional a partir de Dados Domiciliares de 2005 a 2019
}

\author{
Tomás de Faria Balbino $^{1} \mid$ Aline Cristina da Cruz ${ }^{2}$ (D) | Mariangela Furlan Antigo ${ }^{3}$ (D) \\ ${ }^{1}$ Universidade Federal de Minas Gerais. E-mail: tomasbalbino09@gmail.com \\ ${ }^{2}$ Universidade Federal de São João del Rei. E-mail: alinecruz@ufsj.edu.br \\ ${ }^{3}$ Universidade Federal de Minas Gerais. E-mail: maantigo@gmail.com
}

\begin{abstract}
RESUMO
O presente trabalho busca analisar o comportamento da pobreza, nas macrorregiões brasileiras, nos anos de 2005 a 2019, tendo como referência a Abordagem das Capacidades, uma das principais bases teóricas a fundamentar uma visão alternativa da pobreza, com olhar às privações que inibem o desenvolvimento humano. Para isso, calcula-se o Îndice de Pobreza Multidimensional (IPM) para os espaços rurais e urbanos e estima-se Modelos Logit para captar efeitos categóricos da pobreza sobre esses espaços. Os resultados apontam queda na pobreza multidimensional em todas as macrorregiões, no entanto, com diferentes dinâmicas entre pobreza de renda e multidimensional e padrões específicos entre regiões e os espaços rural e urbano. Percebe-se que, ao analisada por diferentes privações, a probabilidade de ser pobre é mais persistente e, de certa forma, mais intensa, nas áreas mais vulneráveis do país, em especial, atingindo a população das áreas rurais do Norte e Nordeste brasileiro.
\end{abstract}

\section{PALAVRAS-CHAVE}

Pobreza, Abordagem das capacidades, Desigualdade regional

Brazilian Rural and Urban Poverty from the Views of Privations: An Regional Analysis From Household Data From 2005 to 2019

\begin{abstract}
The Capability Approach has become one of the main theoretical bases to fundamental an alternative view of poverty, looking at the deprivations that inhibit human development. Using the Capabilities Approach as a reference, the present work aims to analyze the behavior of poverty, in the Brazilian macro-regions, in the years 2005 and 2015. For this, the Multidimensional Poverty Index (MPI) for rural and urban spaces is calculated and Logit Models are estimated to capture categorical effects of poverty on these spaces. The results point to a fall in multidimensional poverty in all macro-regions, however, with different dynamics between income and multidimensional poverty and specific patterns between regions and rural and urban spaces. It is perceived that, when analyzed by different deprivations, the probability of being poor remains persistent and, in a way, more intense, in the most vulnerable areas of the country, in particular, affecting the population of rural areas in the North and Northeast of Brazil.
\end{abstract}

\section{KEYWORDS}

Poverty, Capabilities approach, Regional inequality 


\section{Introdução}

O crescimento econômico brasileiro observado na primeira década do século XXI contribuiu para a diminuição da incidência da pobreza de renda e da miséria no país. Como mostra Osório (2015), os níveis de pobreza monetária diminuíram em valores relevantes, no período entre 2005 e 2015, com aumento da média da renda domiciliar per capita impulsionado por políticas assistencialistas de transferência direta de renda, como o Programa Bolsa Família. A partir de 2016 o país passou por uma mudança em sua trajetória econômica, caracterizada pela adoção de políticas de austeridade fiscal que refletiram diretamente no enfraquecimento de políticas sociais instituídas ao longo da década anterior. Diante disso, analisar os aspectos da pobreza no Brasil, por espaços e regiões, permite compreender o comportamento do fenômeno em contextos distintos da política e economia brasileira.

Ainda que a pobreza de renda seja uma questão que demanda muitos esforços de pesquisadores e gestores públicos, a literatura tem procurado interpretar o fenômeno da pobreza à luz de óticas diferentes, capazes de contemplar maiores diversidades objetivas e subjetivas da vida humana. No fim do século XX, a Abordagem das Capacitações ou Capacidades Humanas ${ }^{1}$ [capabilities approach], proposta por Amartya Sen (1999, 2000, 2001) e Martha Nussbaum (1987, 2000, 2011), trouxe a discussão de diferentes "bases informacionais" utilizadas pelas Ciências Sociais nas construções de juízos avaliativos, como o uso decorrente de utilidade, dotação de bens primários, preferências e da liberdade formal. Buscando fortalecer a base ética das avaliações sociais e interpessoais, Sen (1999) propôs uma base informacional fundamentada na liberdade substantiva individual, a qual, em termos práticos, se refere às possibilidades e oportunidades do indivíduo para realizar e alcançar ações por ele valorizado.

A Abordagem das Capacidades fundamenta uma concepção de pobreza que apresenta alternativas para superar as limitações presentes nas comparações interpessoais pautadas exclusivamente na dimensão da renda, passando a ser interpretada como privações das capacidades humanas (Rego e Pinzani, 2014). Esta interpretação se faz relevante para análises sociais no Brasil, devido às diversidades regionais e à diferenciação entre espaços resultantes do processo de formação social do país. A caracterização dos fenômenos sociais, com o olhar para o rural e o urbano, e de suas estruturas regionais é importante, pois, a investigação de desigualdade dentro da diversidade humana é influenciada por fatores meteorológicos, culturais, ambientais, políticos e sociais distintos de cada região (Sen, 1999; Robeyns, 2005b; Nussbaum,

\footnotetext{
${ }^{1}$ A definição do termo traduzido varia entre capacidades a capacitações, sendo, muitas das vezes, feita segundo os interesses dos autores, no entanto, (Pinheiro, 2012, p. 20) afirma que "é preferível o termo "capacidade" à "capacitação”, pois o último (em português falado no Brasil) denota a ação de capacitar, formar a pessoa para um trabalho especifico. "Capacitação" sempre pode soar como "a atividade de dotar alguém de poder para fazer alguma coisa”. Ainda que esse sentido esteja plenamente de acordo com muitos contextos de uso de capability na obra de Sen, (Pinheiro, 2012, p. 20) menciona que não é geral o suficiente para abarcar o estado de o agente ter oportunidade de alcançar os inúmeros funcionamentos alternativos. Já o termo "capacidade", ainda que não seja ideal, é mais geral do que "capacitação", pois denota a pura potência (no sentido aristotélico mesmo) do sujeito de se alterar, transformar, conquistar, alcançar etc. alguma coisa, seja um estado ou uma atividade" (Pinheiro, 2012).
} 
2011). Além disso, a privação das capacidades também é importante instrumento para distinguir espaços de dinâmicas completamente distintas, incluindo diferentes modos de vida e de reprodução social, o que torna a pobreza um fenômeno diferente entre o meio urbano e o meio rural.

Desse modo, o presente trabalho tem como objetivo principal compreender o comportamento e as características da pobreza, sob a perspectiva de privação de capacidades, no espaço urbano e rural das grandes regiões brasileiras entre 2005 e 2019. Especificamente, visa-se: a) Avaliar a incidência e a intensidade da pobreza nestes espaços, a partir das privações individuais nas dimensões de educação, habitação, saúde e trabalho; e b) Identificar os grupos sociais com maior probabilidade de estar em situação de pobreza de renda e pobreza multidimensional, nos períodos e espaços considerados, segundo características categóricas da pobreza e atributos de raça, escolaridade, gênero e outros.

Abordar a pobreza a partir de uma ótica de privação humana justifica-se pela possibilidade de identificar dimensões que limitam a qualidade de vida do indivíduo e que podem apresentar um peso mais significativo do que a renda. O reconhecimento das condições habitacionais e do acesso a serviços públicos de qualidade como capacidades humana, também permite fazer a leitura de uma realidade escamoteada da desigualdade e da pobreza do país, e indicar que mesmo com a expansão da renda per capita as privações em diversas outras dimensões da vida da população brasileira ainda são persistentes.

No que se refere à estrutura do trabalho, são quatro seções, além da introdução e das considerações finais. Na primeira parte, discute-se a Abordagem das Capacidades, principais conceitos e fundamentos, base do enfoque multidimensional da pobreza. Na segunda parte, apresenta-se, brevemente, as relações próximas e as diferenças presentes entre o rural e o urbano no Brasil, incluindo a importância da observação das capacidades humanas em ambientes diferenciados. Em seguida, são demonstradas as técnicas utilizadas: a construção do Índice de Pobreza Multidimensional (IPM) e as estimações de regressões Logit. Por fim, discutem-se os resultados e características da pobreza por privações na população brasileira.

\section{A Abordagem das capacidades e a pobreza como privação}

A discussão que ganhou força, no final do século XX, por trás da ideia de pobreza se inscreve em uma percepção multidimensional do fenômeno e está fortemente vinculada à Abordagem das Capacidades, tendo como principais autores o economista e filósofo Amartya Sen (1999, 2000, 2001) e a filósofa Martha Nussbaum (1987, 2011). Ademais, é uma perspectiva que conta com importantes contribuições de outros estudiosos, como Ingrid Robeyns (2005a,b), Sabina Alkire e James Foster (2008, 2015).

A Abordagem das Capacidades emerge pelo questionamento à "base informacional” utilizada por teorias tradicionais da Filosofia Política nas análises comparativas 
interpessoais e de juízos avaliatórios. Segundo Sen (1999, 2000), tanto o Utilitarismo antigo, cuja base informacional é a utilidade e a considera enquanto prazer, satisfação e felicidade do indivíduo, quanto o Utilitarismo moderno, o qual considera a satisfação do desejo de escolha pessoal a partir das preferências, limitam a possibilidade para comparações interpessoais ao generalizarem a base informacional, isto é, considerarem a maximização da utilidade total de um conjunto suficiente, o que, segundo o autor, não permite captar as desigualdades na distribuição de utilidades (Sen, 1999, 2000).

Sen $(1999,2000)$ também é crítico ao libertarianismo, que utiliza como avaliação humana as liberdades formais e os direitos, e à teoria da justiça de John Rawls, que reconhece os bens primários que as pessoas possuem para alcançar os objetivos como espaço de comparações interpessoais e juízos avaliatórios. A questão central levantada por Sen (2000) é que tais teorias são incapazes de compreender as inúmeras variações existentes entre os recursos e a sua conversão em realizações, ou seja, converter a renda ou uma cesta de mercadorias em fins valorizados e desejáveis para o indivíduo.

Com base em tais limitações, Sen (1999, 2000, 2001) e Nussbaum (1987, 2011) construíram e propuseram uma abordagem alternativa para avaliação social. Assim, a Abordagem das Capacidades pode ser vista como a teorização de uma nova compreensão comparativa de fenômenos e processos sociais, dando sustentação à uma nova abordagem da pobreza. Nesse novo enfoque, a base informacional utilizada para juízos avaliatórios passa a estar centrada nas liberdades substantivas individuais, e não mais nas utilidades ou bens primários, o que faz com que a pobreza seja analisada por meio das privações sofridas pelo indivíduo.

Para construção desse pensamento, Sen (2001) discute em sua obra "Desigualdade Reexaminada" em qual espaço [dimensão] é tratada a igualdade, quando se pretende fazer comparações interpessoais. Para o autor, para se discutir a ética da igualdade, é necessário fazer a pergunta: "Igualdade de quê?" (SEN, 2001). Dentro do campo científico, a compreensão da igualdade se dava por visões diferentes. No campo econômico, a ideia de igualdade era influenciada pela teoria utilitarista, a qual defendia como igualdade as utilidades desfrutadas por diferentes pessoas, assumindo uma forma de tratamento igual entre todos os indivíduos, em um espaço de ganhos e perdas de utilidade (Sen, 1986, 2000). Já no campo da justiça, cuja proposta era um olhar voltado ao âmbito social, a teoria Rawlsiana via a igualdade em termos de bens primários sociais, vinculados às oportunidades pessoais pressupostas pelos princípios da justiça.

Dadas as diferentes interpretações que cercam a compreensão de igualdade, a principal questão passa a ser o "espaço de avaliação". Ao considerar a existência de uma diversidade humana generalizada, o diagnóstico da desigualdade não se pode basear em apenas uma variável focal, mas sim em uma pluralidade de variáveis. Desse modo, o questionamento que norteia a discussão de Sen é: Gual parâmetro utilizar 
em estudos de desigualdade, de forma a ter valores éticos como base? Liberdades, direitos, utilidades, rendas, bens primários, etc.? (Sen, 1999, 2001).

Para visualizar a desigualdade por uma nova ótica, Sen demonstra que o ordenamento social pode ser julgado por duas perspectivas: a realização de fato conseguida e a liberdade para realizar. Assim, a desigualdade passa a ser vista em termos de "realizações e liberdades". Segundo o autor, o entendimento de "liberdade" difere da noção de "realização" individual que é a de termos ou alcançarmos algo, e se torna "a oportunidade real que temos para fazer ou alcançar aquilo que valorizamos" (Sen, 1999, p. 69).

Sen (2000) introduz os conceitos de funcionamentos [functionings] e capacidades [capabilities] para instrumentalizar essa percepção de liberdade. Os funcionamentos remetem a um conjunto de estados e ações almejados pelo indivíduo, dando origem ao termo "liberdade de funcionamentos", como proposto por Sen (1999). Esses funcionamentos podem variar desde estar bem alimentado até realizações mais complexas, como estar feliz. Já as capacidades representam as diferentes combinações de funcionamentos, cuja realização é factível. Nesse sentido, as capacidades representam a liberdade substantiva do indivíduo em realizar diferentes combinações de funcionamentos, sendo essa liberdade o espaço de comparações e juízos da Abordagem das Capacidades, a qual, em termos práticos, se refere à possibilidade e oportunidade do indivíduo em realizar ações e alcançar estados pelo mesmo valorizados e considerados essenciais. Nesse sentido, a pessoa que possui um conjunto maior de capacidades consegue escolher entre um número maior de diferentes opções de funcionamentos, aumentando, assim, a sua liberdade diante de uma decisão ${ }^{2}$.

Nussbaum (2000) apresenta diferentes formas de enxergar as capacidades, as dividindo entre: capacidades internas, que referem-se a condições (corpóreas, mentais, etc.) que viabilizam a capacidade de escolha entre diversos funcionamentos; as capacidades externas, que representam as condições materiais e sociais disponíveis, as quais permitem ao indivíduo escolher por determinadas opções; as capacidades combinadas, que representam a interação das capacidades internas de um indivíduo com o ambiente social, político e econômico no qual se insere; e, as capacidades básicas, que estão presentes no indivíduo e necessitam de desenvolvimento para promover vida digna, e que se desenvolvem a partir do contexto social do indivíduo. A diversidade das capacidades enfatiza o fato de que os elementos mais importantes da qualidade de vida dos indivíduos são plurais e qualitativamente distintos, desse modo, como afirma Nussbaum (2011), os aspectos da vida das pessoas não podem ser reduzidos a uma única métrica sem distorção.

A relevância das capacidades enquanto base informacional alternativa pode ser

\footnotetext{
${ }^{2}$ Segundo (Sen, 2001, p. 80), "tal como existe um conjunto orçamentário no espaço das mercadorias que representa a liberdade para o indivíduo comprar pacotes de mercadorias, existe um conjunto "capacitário" no espaço de funcionamentos, que representa a liberdade da pessoa para escolher entre vidas possiveis".
} 
vista por meio da análise da pobreza, fenômeno este com diferentes abordagens que o identifica e conceitua a partir da subsistência, das necessidades básicas, da renda e das multidimensões que cercam a qualidade de vida (Codes, 2008). Entretanto, como afirma Sen (2001), embora o conceito de pobreza possa ser utilizado de modos diferentes, existem algumas associações claras que restringem sua natureza. A grande diferença suscitada pela Abordagem das Capacidades na compreensão da pobreza diz respeito à conversão de meios em fins. Essa diferença diz respeito às diversidades de variações existentes entre os meios que as pessoas possuem (conjunto capacitário, como nivel de renda e cesta de mercadorias, por exemplo) e as realizações que elas podem promover (funcionamentos).

Um exemplo pode ser visto na relação entre a renda e as capacidades. Ainda que o papel da renda seja meramente útil, principalmente, ao considerar a liberdade que o indivíduo pode adquirir em outras capacidades, esta deve ser integrada em um quadro mais amplo e complexo de privações (Sen, 2000). (Sen, 2000, p. 110) menciona que a renda pode ser fortemente afetada "pela idade da pessoa (necessidades específicas dos idosos e muito jovens), pelos papéis sociais e sexuais (responsabilidades da maternidade, obrigações familiares, etc.), pela localização (propensão a inundações ou secas, insegurança e violência), por condições epidemiológicas (doenças endêmicas em alguma região), entre outros", o que aumenta a complexidade sobre a compreensão das privações humanas.

Sen (2000) elenca cinco fontes que distinguem a relação entre a renda e o bemestar dela decorrente, o que diferencia a capacidade de cada indivíduo em converter a renda em funcionamentos. Há as heterogeneidades pessoais (idade, sexo, localização) as quais diferem das necessidades individuais. Inclui-se as diversidades ambientais, as quais se referem às variações nas condições ambientais (temperatura, níveis pluviométricos, etc.). Tem-se também as variações no clima social, que modificam as condições sociais e também influenciam na conversão de renda em bem-estar, como a estrutura do serviço público, a presença de violência, epidemiologias, dentre outros; cabendo elencar as diferenças de perspectivas relativas, nas quais determinado nivel de renda pode significar riqueza em certa região, e, pobreza em outra. Outra fonte é a distribuição na família, uma vez que o bem-estar dos membros de uma família diverge de acordo com o modo como a renda familiar é usada na promoção dos interesses dos membros ${ }^{3}$.

É a partir da noção de liberdades substantivas e da compreensão da privação dessas liberdades que a ideia de pobreza como privação se torna concreta. Quando o indivíduo possui privação em alguma capacidade - direito à moradia, acesso à serviços de saúde, saneamento básico ou água tratada, acesso à educação, habitar em

\footnotetext{
${ }^{3}$ Os atributos mencionados podem reduzir a capacidade do indivíduo não apenas de adquirir renda, mas fazer com que essa renda se torne estados e ações desejadas. Entende-se que, para realizar determinados funcionamentos, a partir de certo montante de renda, um indivíduo com idade mais avançada, ou com alguma doença, demandará quantidade de renda maior, superior ao usual utilizado para realizar os mesmos funcionamentos. Isso mostra que a "pobreza real" (privação de capacidades) pode ser mais intensa do apenas sob o olhar da renda.
} 
região com doenças epidêmicas ou secas sistêmicas, etc., ou mesmo, sofrer privações de sua liberdade política, jurídica e social, ele se encontra em determinado nível de pobreza. Desse modo, quanto maior a privação sistemática de oportunidades, mais restringida é a liberdade do indivíduo para tomar suas decisões (Sen, 2000). Nesse sentido, a pobreza pode ser entendida como uma privação ou um conjunto de privações de capacidades do indivíduo, as quais restringem os funcionamentos que lhes garantem liberdade para escolher o modo de vida pelo mesmo valorizado. Nas palavras de (Rego e Pinzani, 2014, p. 74): “a pobreza não é somente privação de dinheiro e recursos materiais, é também privação de capacidades e não desenvolvimento de funções humanas importantes, o que tende a tornar os pobres ainda mais pobres”.

Como mostrado por Sen (1999, 2000) e Nussbaum (2000), além dos elementos objetivos e econômicos, existem elementos subjetivos e éticos que geram privações para os indivíduos. Dentre um universo de componentes objetivos e subjetivos considerados componentes da pobreza, alguns são elencados em outras obras para facilitar o entendimento por trás dessa abordagem, a saber: i) falta de condições básicas para uma vida saudável; ii) acesso nulo ou irregular à renda derivada de um trabalho regular; iii) trabalho infantil e abandono escolar; iv) alta natalidade; v) acidentes; vi) falta de crédito; vii) invisibilidade e mudez; viii) desigualdade interna às famílias; ix) vergonha; x) cultura de resignação; xi) exclusão da cidadania (Rego e Pinzani, 2014). Desse modo, segundo Comim et al. (2006), a principal contribuição da teoria da Abordagem das Capacidades é expandir o espaço informacional ao nível da liberdade substantiva pessoal e permitir que as pessoas escolham uma vida que consideram mais valiosa. Nesse sentido, deve-se considerar que a estrutura da pobreza compete elementos objetivos e subjetivos, éticos e econômicos, materiais e abstratos.

\section{O rural e o urbano brasileiro sob a perspectiva das capa- cidades}

Uma vez compreendido que as capacidades representam um espaço de avaliação que preconiza a heterogeneidade humana, a diferenciação espacial se torna importante elemento de observação crítica dos fenômenos sociais, uma vez que as diferentes formas de construção dos espaços geram diferentes privações ao indivíduo. Como menciona Nussbaum (2011), as capacidades devem ser compreendidas tanto como internas aos indivíduos, mas também em sua natureza combinada, o que se refere às capacidades inseridas no ambiente social, econômico e político. Robeyns (2005b) também menciona a importância da observação espacial das capacidades, pois fatores regionais que envolvem questões de cultura local, tradicionalismo, vegetação e clima influenciam diretamente na transformação de bens em funcionamentos, assim como também aponta Sen (1999) para a influência de fatores meteorológicos, culturais e sociais na diversidade humana.

No caso brasileiro, compreender as diferenças entre o meio rural e urbano repre- 
senta a observação de um processo histórico em constante mutação no país. Ainda que haja diferenciações entre a definição do urbano e do ural $^{4}$, o importante a saber é que ambos os espaços fazem parte de um continuum da formação social do Brasil e, por isso, têm a natureza dos principais problemas sustentadas pelo mesmo fenômeno: a desigualdade social (Wanderley, 2014). As aglomerações dos centros urbanos tão evidenciadas pelas favelas, as condições de vida insalubre na qual vivem boa parte dos trabalhadores das grandes cidades do país, entre outras problemáticas sociais causadas pela explosiva urbanização, refletem, não apenas, incapacidade histórica dos políticos brasileiros em compreender a realidade e os modos de vida por trás da população que um dia se encontrou no meio rural, mas também da sustentação de uma estrutura social desigual diferenciada pelas classes, raças e regiões.

A desigualdade social do país, materializada na renda e na terra, é a origem dos problemas observados em ambos os espaços. Essa desigualdade emerge ainda no período em que o Brasil era um país extensivamente rural, quando significativa parte da população habitava o campo e a economia do país era movida por atividades agropecuárias exportadoras. Nesse cenário, a Lei de Terras, em 1850, marca um importante momento, após o período escravocrata, em que a desigualdade passa a ser alimentada pela propriedade privada, tendo em vista que o direito à livre comercialização das terras era um privilégio de uma minoria oligárquica já beneficiada pelas contradições econômicas do país (Martins, 2010). À população pobre, marcada por pretos, indígenas e imigrantes, restou a venda da mão de obra em troca de teto, comida e água, mantendo assim uma estrutura desigual presente desde o período colonial.

Com os meios de sobrevivência cada vez mais privados no meio rural, como terra e água, as populações desses espaços foram, gradativamente, migrando para as cidades. A partir da década de 1930, e, em especial, a partir da década de 1950, o fluxo migratório do campo para as cidades aumentou, vertiginosamente, e, desde então, vem se mantendo constante. Vários motivos representam essa transição populacional, no entanto, a modernização do campo e a industrialização brasileira se mostram como as principais causas. Por um lado, a modernização chegou até o campo como sinônimo de progresso e produtividade em uma sociedade marcada pelas técnicas arcaicas. Contudo, esse fenômeno representou o aumento descontrolado da concentração de terras, a deterioração dos recursos hídricos e o consequente aumento de diversas privações das populações que se reproduziam no meio rural (Silva, 1980; Ribeiro, 1997). Por outro lado, a crescente indústria nas cidades demandava tanto mão-de-obra quanto um mercado interno consumidor, o que acabou se tornando para a população rural sinônimo de melhora na qualidade de vida. Wanderley (2014) re-

\footnotetext{
${ }^{4} \mathrm{O}$ debate literário acerca das definições de rural e urbano é vasto, complexo e indefinido (IBGE, 2017). Como menciona Serra (2017), diferentes tipologias utilizadas para caracterizar o meio rural brasileiro, com destaque às que identificam o rural, a partir do tamanho populacional, da densidade demográfica e da localização do município, levam a uma série de pequenos e médios municípios serem considerados rurais. Essa tipologia é pertinente para pensar o desenvolvimento regional, pois permite compreender as dinâmicas entre pequenas cidades, suas áreas rurais e relações com a região, no entanto, nesse trabalho, a definição de rural e urbano segue a proposta censitária feita IBGE para a PNAD.
} 
trata essa origem, ao afirmar que:

Os territórios rurais são frágeis e concentram pobreza, pois foram abandonados no século XX, quando o Brasil privilegiou investimentos nos grandes centros urbanos, na ânsia de se tornar potência industrial no âmbito mundial. [...] O hiato entre o Brasil urbano e a grande maioria dos territórios rurais é uma herança do processo de desenvolvimento herdado (Wanderley, 2014, p. 204).

Desse modo, compreender as capacidades, a partir de uma dimensão espacial, representa a combinação dessas capacidades ao ambiente social, político e econômico, no qual foram historicamente construídas. É perceptivel que as privações entre a população urbana e a população rural no Brasil apresentam aproximações e diferenças. A falta de saneamento básico, educação e serviços públicos de qualidade é vista em ambos ambientes. A criminalidade, a superlotação do transporte público e as grandes distâncias entre casa e trabalho refletem algumas privações comuns nos grandes centros urbanos brasileiros, enquanto a falta de recursos produtivos, a falta de renda, a longa distância de centros urbanos, o acesso à agua potável, à coleta de lixo e à eletricidade representam algumas das privações observadas no território rural brasileiro (Wanderley, 2014).

As capacidades apresentam relevância para os estudos rurais devido ao fato de que a pobreza, nesses espaços, se diferencia muito da simples privação de renda, se expandindo para as possiblidades de plantio e criação de animais, disponibilidade de recursos hídricos e condições de infraestrutura. Wanderley (2014), em "Campesinato brasileiro: uma história de resistência”, discute como ainda existe uma população rural extremamente vulnerável no país, mesmo depois das políticas sociais e rurais do século XXI. Essas populações representam agricultores pobres localizados em áreas de baixa produção, comunidades quilombolas afastadas e desassistidas, comunidades indígenas e ribeirinhas.

A constatação das capacidades também tem contribuído para os estudos rurais do desenvolvimento. Dentro da literatura, a noção de capacidades passou a ser associada aos meios de vida [livelihoods] das populações rurais, com importantes contribuições nas visões de desenvolvimento rural, como observado em Bebbington (1999) e Chambers e Conway (1991). Nos estudos brasileiros, o conceito de capacidades tem apresentado maiores relações com o tema da qualidade de vida, a qual, na visão de Schneider e Freitas (2013), foi definida por Nussbaum e Sen (1996) como as combinações entre capacidades e funcionamentos do indivíduo.

Nesse sentido, o presente trabalho busca alimentar o debate entre as diferenças do rural e do urbano por meio de uma investigação mais recente de forma a apontar os efeitos espaciais da pobreza multidimensional no período entre 2005 e 2019 . Observar o comportamento da pobreza por região e por áreas urbanas e rurais pode apontar não apenas para as mudanças na trajetória da pobreza, mas também para o padrão das desigualdades que se modifica ou persiste diante dessas mudanças. 


\section{Estratégias empiricas}

\subsection{O Índice de Pobreza Multidimensional (IPM), segundo a abordagem das capacidades}

Com o objetivo de instrumentalizar a pobreza, sob à ótica da Abordagem das Capacidades, Alkire e Foster (2008) desenvolveram o Índice de Pobreza Multidimensional (IPM), levando em consideração a privação de liberdades dos indivíduos em determinadas dimensões. Uma das vantagens apontada pelos autores e pela literatura (Comim et al., 2006; Alkire et al., 2015), no uso do IPM, é sua capacidade de interpretar as características da pobreza, ao captar as principais privações de determinados grupos ou regiões. O indicador é utilizado em mais de cem países em desenvolvimento, dado que a compreensão da incidência da pobreza por dimensões pode auxiliar gestores públicos no direcionamento de políticas voltadas à erradicação da pobreza e ao desenvolvimento social (Vieira et al., 2014). A metodologia utilizada por Alkire e Foster (2008) também permite verificar outros fenômenos para além da pobreza, como o desenvolvimento, tendo sido aplicado pelo Programa de Desenvolvimento das Nações Unidas (PNUD) para informar o comportamento dos Objetivos de Desenvolvimento Sustentável (ODS) propostos pela Organização das Nações Unidas (ONU) (PNUD, 2019).

Especificamente, Sen (2000) sugere duas etapas metodológicas para definir a pobreza: identificar os pobres em determinada população; e, considerar as diferentes características comuns aos pobres na avaliação do nível de pobreza na amostra analisada. Para isso, Alkire e Foster (2008) utilizam dois tipos de cortes num espaço multidimensional. O primeiro configura uma linha de corte de privação, na qual se define se o indivíduo é ou não privado naquele indicador. O segundo é uma linha de corte da pobreza - definida a partir da quantidade de indicadores que o indivíduo é privado.

As escolhas das dimensões e dos indicadores são fundamentadas no conjunto capacitário do indivíduo ${ }^{5}$, havendo um embate na literatura referente a quais recursos são importantes para tornar as capacidades relevantes (Robeyns, 2005a). Robeyns (2005a) afirma que Sen sempre se absteve de se comprometer com uma lista particular de variáveis representantes das capacidades. Cada forma de abordagem das capacidades irá sempre ser combinada a outra teoria social, dando conta de diferentes capacidades e funcionamentos, o que não permite criar uma lista única e um padrão do que viria a ser essas ações (Sen, 1993, 2004)robeyns2005capability. Contudo, Robeyns (2005b) menciona que existem alguns critérios aplicados à seleção dos indicadores, de forma a evitar preconceitos epistemológicos na elaboração do indicador

\footnotetext{
${ }^{5}$ Pela Abordagem das Capacidades, a privação da liberdade é um fator subjetivo e intrínseco a cada ser humano. Nesse sentido, na representação direta da teoria, faz-se necessária uma metodologia calcada na pesquisa de campo, identificando em toda a amostra o conjunto capacitário e os funcionamentos de cada indivíduo, como em Comim et al. (2006) e Bagolin et al. (2012) em estudos sobre pobreza e gênero em Porto Alegre. Entretanto, Sen (2000) afirma que, para avaliações sociais de escala mais elevadas, a limitação de identificar as capacidades deve se dar por meio de "consenso" sobre dimensões fundamentais ao bem-estar de uma pessoa (acesso à água, alimentos, educação, saúde, entre outros).
} 
social. Esses critérios são: i) formulação explícita dos indicadores utilizados; ii) embasamento metodológico para justificar os usos dos indicadores; iii) diferentes níveis de generalidade, abordando estágios distintos da situação analisada; e, iv) exaustão e não redução dos indicadores, na busca de incluir todos os elementos considerados importantes na análise.

No presente estudo, os indicadores e dimensões foram selecionados, a partir de microdados da Pesquisa Nacional de Amostras Domiciliares (PNAD) dos anos de 2005 a 2015, e da Pesquisa Nacional de Amostras Domiciliares Contínua (PNAD Contínua) dos anos de 2016 a 2019 do Instituto Brasileiro de Geografia e Estatística (IBGE), com o objetivo de obter mudanças espaciais na dinâmica da pobreza multidimensional brasileira. Foram consideradas três dimensões na construção do IPM - educação; condições habitacionais e saúde; trabalho e riqueza, além de treze indicadores ligados à linha de corte de privação, como pode ser visto no Guadro ??. No que concerne ao não consenso na literatura sobre indicadores e dimensões viáveis para melhor retratarem as capacidades, este estudo segue o senso comum sobre capacidades essenciais para todo ser humano. A despeito das limitações nas informações disponibilizadas pelos microdados, as dimensões escolhidas são capazes de refletir um universo multidimensional de privações. Outros diversos trabalhos também utilizaram dimensões similares às aqui definidas como se vê no Quadro ??.

Quanto à primeira linha de corte estabelecida, esta é relacionada à carência do indivíduo em cada indicador, ao passo que a segunda linha de corte é definida a partir do resultado dos valores somados na contagem das privações de todos os indicadores, definindo os indivíduos pobres com base no número de privações definidoras da linha da pobreza. Segundo Alkire e Foster (2008), essa linha da pobreza é obtida de maneira muito intuitiva, ficando a cargo do pesquisador definir a quantidade de privações necessárias para considerar o indivíduo pobre. No presente trabalho, considera-se que indivíduos privados em cinco ou mais indicadores são indivíduos pobres.

De posse dos resultados das privações e da definição da linha da pobreza, obtémse um grupo de pessoas multidimensionalmente pobres. A próxima etapa é calcular o primeiro componente do IPM, a incidência de pobreza (H-Headcount), o qual mostra a proporção de indivíduos pobres do total de indivíduos da amostra, como visto a seguir:

Headcount $(H)=\frac{\text { número de pessoas abaixo da linha de corte }(\text { consideradas pobres })(q)}{\text { número total de pessoa da amostra }(a)}$

Ao considerar o Headcount como a proporção de pobres no conjunto analisado, seria possivel considerar que sua utilização já seria suficiente para avaliar o índice de pobreza, contudo, existe uma deficiência nesse instrumental. Caso um indivíduo que já é pobre se torne privado em mais uma dimensão, o número de privações aumenta, porém, a incidência da pobreza $(\mathrm{H})$ continua a mesma. Desse modo, a pessoa 
Guadro 1. Construção do IPM: dimensões, indicadores, linhas de privação e pesos.

\begin{tabular}{|c|c|c|c|}
\hline Dimensões & Indicadores & Não privado se ... & Peso \\
\hline \multirow{4}{*}{ Educação } & $\begin{array}{l}\text { Domicílios com crianças de } 4 \text { e } 5 \\
\text { anos que não frequentam a pré- } \\
\text { escola }\end{array}$ & $\begin{array}{l}\text { Não possuir nenhuma criança, } \\
\text { nessa faixa de idade, que não fre- } \\
\text { quenta e escola }\end{array}$ & $1 / 12$ \\
\hline & $\begin{array}{l}\text { Domicílios com jovens de } 18 \text { a } 20 \\
\text { anos com ensino médio incom- } \\
\text { pleto }\end{array}$ & $\begin{array}{l}\text { Não possuir nenhum jovem, nessa } \\
\text { faixa de idade, com ensino médio in- } \\
\text { completo }\end{array}$ & $1 / 12$ \\
\hline & $\begin{array}{l}\text { Domicílios com crianças entre } 6 \\
\text { e } 17 \text { anos que não frequentam a } \\
\text { escola }\end{array}$ & $\begin{array}{l}\text { Não possuir nenhum indivíduo, } \\
\text { nessa faixa de idade, não frequen- } \\
\text { tando a escola }\end{array}$ & $1 / 12$ \\
\hline & Analfabetismo funcional & Não possuir analfabetos funcionais & $1 / 12$ \\
\hline \multirow{6}{*}{$\begin{array}{l}\text { Condições } \\
\text { habitacionais } \\
\text { e de saúde }\end{array}$} & Água canalizada & $\begin{array}{l}\text { Possuir água canalizada em pelo } \\
\text { menos um cômodo do domicílio }\end{array}$ & $1 / 18$ \\
\hline & Destino do Lixo do Domicílio & $\begin{array}{l}\text { Colocar o lixo, ao menos, em uma } \\
\text { caçamba do serviço de limpeza }\end{array}$ & $1 / 18$ \\
\hline & Esgoto sanitário & $\begin{array}{l}\text { Possuir ligação com rede de esgoto } \\
\text { ou pluvial, de forma direta ou indi- } \\
\text { reta }\end{array}$ & $1 / 18$ \\
\hline & Ativos & $\begin{array}{l}\text { Possuir telefone ou celular, televisão } \\
\text { ou rádio, geladeira e máquina de la- } \\
\text { var }\end{array}$ & $1 / 18$ \\
\hline & Presença de idoso no domicílio & $\begin{array}{l}\text { Não possuir idosos maior de } 65 \text { anos } \\
\text { no domicílio. }\end{array}$ & $1 / 18$ \\
\hline & $\begin{array}{l}\text { Domicílios com mais de } 3 \text { pes- } \\
\text { soas por dormitório }\end{array}$ & $\begin{array}{l}\text { Não possuir dormitório com mais de } \\
3 \text { pessoas }\end{array}$ & $1 / 18$ \\
\hline \multirow{3}{*}{$\begin{array}{l}\text { Trabalho e } \\
\text { Riqueza }\end{array}$} & $\begin{array}{l}\text { Trabalhador que não contribui } \\
\text { com a previdência }\end{array}$ & $\begin{array}{l}\text { Trabalhadores acima de } 18 \text { anos } \\
\text { que não contribuem para a previ- } \\
\text { dência }\end{array}$ & $1 / 9$ \\
\hline & Desemprego & $\begin{array}{l}\text { Não possuir no domicílio nenhum } \\
\text { adulto desempregado }\end{array}$ & $1 / 9$ \\
\hline & Imóvel Próprio & Possuir imóvel próprio & $1 / 9$ \\
\hline
\end{tabular}

Fonte: Elaboração própria a partir de dados da PNAD (2005-2015) e da PNAD Contínua (2016-2019).

Guadro 2. Aplicação do IPM na literatura: localidades e dimensões consideradas.

\begin{tabular}{|l|c|l|}
\hline \multicolumn{1}{|c|}{ Autores } & Localidade & Dimensões consideradas \\
\hline $\begin{array}{l}\text { Comim, Bagolin, Ávila, Porto } \\
\text { Júnior e Picolotto (2006) }\end{array}$ & Porto Alegre & $\begin{array}{l}\text { Nutrição, saúde, educação, } \\
\text { conhecimento, participação, } \\
\text { confiança, etc. }\end{array}$ \\
\hline Vieira, Kuhn e Marin (2017) & Rio Grande do Sul & $\begin{array}{l}\text { Educação, condições domici- } \\
\text { liares, de saúde e sanitárias, } \\
\text { renda e trabalho }\end{array}$ \\
\hline Fahel, Leite e Teles (2014) & Brasil & $\begin{array}{l}\text { Educação, saúde, padrão de } \\
\text { vida }\end{array}$ \\
\hline Amores (2014) & Equador & $\begin{array}{l}\text { Educação, saúde, padrão de } \\
\text { vida. }\end{array}$ \\
\hline Serra (2017) & Brasil (urbano e rural) & Padrão de vida e educação \\
\hline
\end{tabular}

Fonte: Elaboração própria. 
intensifica sua condição de pobreza, mas o indicador não capta tal experiência (Alkire e Foster, 2008; Alkire et al., 2015). Para correção, realiza-se o cálculo do hiato da pobreza (A), a porcentagem de pobreza de cada pessoa pobre, ou seja, a média da proporção de privação entre os pobres. Essa nova cifra é considerada o medidor da intensidade da pobreza, ou seja, a distância do indivíduo em relação à linha de pobreza. Esse cálculo é realizado pela divisão da soma das proporções de privações dos indivíduos pela quantidade de indivíduos privados ${ }^{6}$.

$$
\text { Hiato da Pobreza }(A)=\frac{\text { soma das proporções das privações de indivíduos }(c(k) / d)}{\text { quantidade de indivíduos privados }}
$$

Por fim, a partir de ambos os elementos, é possivel calcular o Índice de Pobreza Multidimensional, ou incidência ajustada $\left(M_{0}\right)$, como sendo a proporção de privações que a população pobre enfrenta em relação ao máximo de privações que toda população poderia sofrer. Esse resultado se dá pelo produto entre o Headcount (H) e o hiato da pobreza (A), ou seja, é consequência do produto entre a incidência e a intensidade da pobreza. Desse modo, o índice de pobreza é calculado com a seguinte função:

$$
M_{0}=\mathrm{IPM}=\text { Headcount }(H) \times \text { Hiato da } \operatorname{Pobreza}(A)
$$

\subsection{Modelos de regressão Logit}

A segunda técnica adotada baseia-se na definição de uma modelagem econométrica multivariada voltada à estimação da probabilidade de ocorrência da pobreza monetária e multidimensional nas áreas urbanas e rurais, segundo cada grupo categórico considerado. Para isso, estima-se modelos de escolha qualitativa de distribuição logística, definidos como modelo Logit, a partir dos dados empilhados da PNAD (20052015) e PNAD Contínua (2016-2019). Como o Logit é um modelo de resposta binária o interesse reside na probabilidade de resposta $\left[p_{i}=P\left(y_{i}=1 \mid x_{i}\right)\right]$, ou seja, na probabilidade pi de yi ser igual a um. Considerando o presente trabalho, compreende-se que a probabilidade de o evento ocorrer (do indivíduo ser pobre) é $p_{i}$ e a probabilidade de não ocorrer (não ser pobre) é $\left(1-p_{i}\right)$, como a seguir:

$$
\begin{gathered}
p_{i}=\frac{e^{z}}{1+e^{z}} \\
1-p_{i}=\frac{1}{1+e^{z}}
\end{gathered}
$$

em que $Z=\beta_{0}+\beta_{1} X$. Nesse caso, em uma função de distribuição logística a pro-

\footnotetext{
${ }^{6}$ Por exemplo, ao considerar uma amostra com 5 indivíduos e 5 indicadores, a soma das proporções refere-se à soma da quantidade de privações, dividida pela quantidade de indicadores de cada indivíduo.
} 
babilidade $p_{i}$ varia entre zero e um, de acordo com o valor assumido pelo regressando.

É pertinente mencionar que, pela natureza dos dados, a regressão não pode ser estimada pelos Mínimos Quadrados Ordinários (MQO), uma vez que uma variável resposta entre 0 ou 1 para uma unidade da amostra pode representar um valor do logaritmo natural indefinido. Desse modo, para a estimação dos parâmetros é necessário recorrer a procedimentos de estimação não lineares, como o Método da Máximo Verossimilhança (MMV) (Gujarati e Porter, 2008; Wooldridge, 2010).

Considerando um modelo linear nos parâmetros $\left(\beta_{i}\right)$ e nas variáveis explicativas $\left(X_{i}\right)$, a equação de distribuição logística utilizada para a regressão pode ser vista como:

$$
L_{i}=\ln \left(\frac{P_{i}}{1-P_{i}}\right)=\beta_{0}+\beta_{1} X+u_{i}
$$

em que $\left(\frac{P_{i}}{1-P_{i}}\right)$ representa a razão de chances em favor da ocorrência do evento menos a razão da probabilidade de ocorrência contra a probabilidade de não ocorrência (Gujarati e Porter, 2008).

O coeficiente angular $\left(\beta_{1}\right)$ da regressão representa um coeficiente parcial e estima a variação no Logit estimado decorrente de variação unitária do valor do regressor dado (coeteris paribus). Desse modo, se o valor do coeficiente for positivo, indica que as chances de a variável dependente ser igual a 1 aumentam, ou seja, as chances de se obter sucesso no evento esperado tendem a aumentar, e, caso seja negativo, essas chances irão diminuir (GUJARATI et al., 2008, WOOLDRIDGE, 2010). Isso equivale a dizer que o coeficiente angular mede a variação da probabilidade de ser pobre, mediante a variação de uma unidade na variável categórica $X_{i}$.

Para fins desse trabalho, os modelos Logit tem como variáveis dependentes a probabilidade de o indivíduo ser pobre em termos de renda e a probabilidade do indivíduo ser pobre em termos multidimensionais. Como os dados da PNAD e PNAD Contínua não são diretamente comparáveis, realizou-se quatro regressões: uma para pobreza monetária e outra para pobreza multidimensional, tanto para os dados empilhados da PNAD, quanto para os dados empilhados da PNAD Contínua. Como o IPM concede a porcentagem média de indivíduos privados em um número $z$ de dimensões, utiliza-se como variáveis dependentes as seguintes relações: a) Privação multidimensional - privação em pelo menos cinco indicadores obtido pelo IPM; e b) Privação de renda - renda per capita igual ou menor à linha da pobreza estabelecida pelo Programa Bolsa Família (PBF), segundo os seguintes valores: R\$100,00 (2005), R\$120,00 (2006-2008), R\$140,00 (2009-2013), R\$154,00 (2014-2015), R\$170,00 (2016-2017), $\mathrm{R} \$ 178,00$ (2018-2019).

Em relação às variáveis de controle, parte-se da ideia proposta por Robeyns (2005a) de que há grupos de fatores que influenciam a relação entre um bem e os funcionamentos para alcançá-los. Primeiramente, tem-se os fatores pessoais e suas extensões 
no ambiente social, como: condição física, gênero, políticas públicas, práticas discriminatórias que envolvam racismo, xenofobia, dentre outros. O segundo grupo trata de fatores regionais ligados, por exemplo, a questões de cultura local, tradicionalismo, como também de vegetação e clima.

Desse modo, as variáveis categóricas $\left(X_{i}\right)$ utilizadas são: sexo (homem ou mulher); cor (brancos/amarelos ou preto/pardos); condição no domicílio (chefe ou não); macrorregião (Norte, Nordeste, Centro-Oeste, Sudeste ou Sul); idade (14 a 24, 25 a 44, 45 a 64, 65 anos ou mais); anos de estudo ( 0 a 4, 5 a 7, 8 a 10, 11 anos ou mais de estudos) e espaço (rural ou urbano). As categorias de referência são: rural, Sudeste, mulher, pretos/pardos, 11 anos ou mais de estudo, 65 anos ou mais de idade, chefe de domicílio. Além disso, utilizando-se dos dados empilhados, considera-se as variáveis temporais de ano: 2005 a 2015 para a PNAD, 2016 a 2019 para a PNAD Contínua, sendo os anos de 2005 e 2016 as variáveis de referência. Tal estimação permite compreender o comportamento da pobreza ao longo do ano, possibilitando a interpretação do fenômeno em contextos diferentes.

\section{Análise e discussão dos resultados}

\subsection{A pobreza multidimensional no Brasil, sob a ótica das privações de 2005 a 2019}

Diante da proposta de pesquisa de avaliar a evolução e os traços da pobreza brasileira urbana e rural, sob a perspectiva de privação de capacidades, inicia-se a discussão pelas Figuras 1 e 2, cujos resultados tratam do Índice de Pobreza Multidimensional (IPM) nos espaços rural e urbano das regiões do Brasil, dos anos de 2005 a 2019. Os resultados permitem observar um ponto de inflexão na trajetória de desenvolvimento do Brasil, com base na pobreza por privações. O ano de 2015 marca o momento no qual a trajetória de crescimento da economia brasileira é interrompida e o país vivencia uma grave crise econômica dentro de um período de políticas de austeridade fiscal que comprometem diversas políticas públicas de cunho social. Sendo assim, o período abrangido pelas bases permite compreender tanto uma fase de crescimento econômico e expansão do gasto público, quanto um momento de crise econômica e austeridade fiscal. Ainda que as bases sejam distintas e os resultados não possam ser estritamente comparados, pode-se compreender o comportamento da tendência e estrutura da pobreza por espaços e regiões.

Observa-se, primeiramente, que o Índice de Pobreza Multidimensional denota comportamento decrescente em todas as regiões, tanto no meio rural, quanto no urbano, em todo o período analisado. Trata-se de um indicativo de que a pobreza por privações não apresenta extensão mais expressiva no período recente, muito provavelmente, em decorrência das políticas de proteção social, acesso à educação e infraestrutura adotadas pelo país, ao longo das primeiras décadas do século XXI (Dedecca, 2013; Aquino e Nascimento, 2006; Medeiros e Oliveira, 2020). Inclui-se ainda a valorização do sa- 
lário mínimo real, a criação e expansão do Programa Bolsa Família, a diminuição do desemprego e o crescimento econômico do país nos primeiros quinze anos do século atual (Monteiro Neto, 2014; Cardoso, 2016), com impactos diretos e indiretos nos indicadores analisados, reforçando a discussão do papel central da renda na diminuição da pobreza multidimensional (Sen, 2000; Rego e Pinzani, 2014). As políticas educacionais de fortalecimento do Programa Brasil Alfabetizado e Educação de Jovens e Adultos (EJA), do ensino médio técnico, por meio dos institutos federais de ensino, bem como de expansão do acesso ao ensino superior e das políticas habitacionais como o Programa "Minha casa, minha vida" - também se revelam fundamentais para a diminuição das privações correspondentes aos indicadores aqui tratados.

Figura 1. Índice de Pobreza Multidimensional, no meio rural, por regiões do Brasil, 2005-2019.

(a) 2005-2015

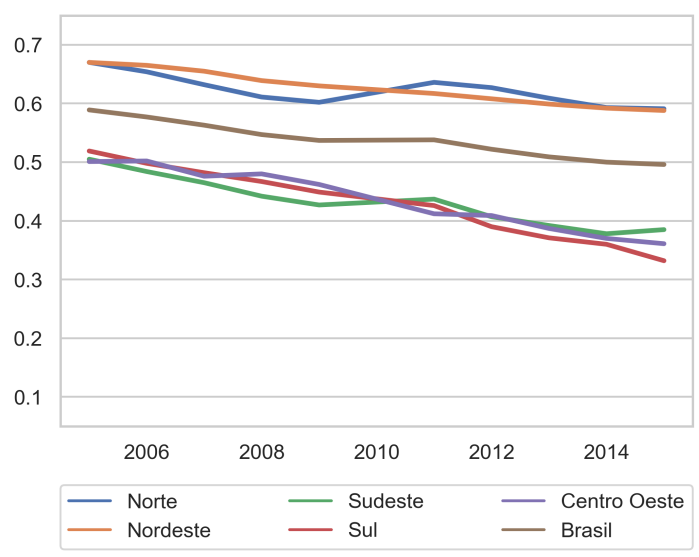

(b) 2016-2019

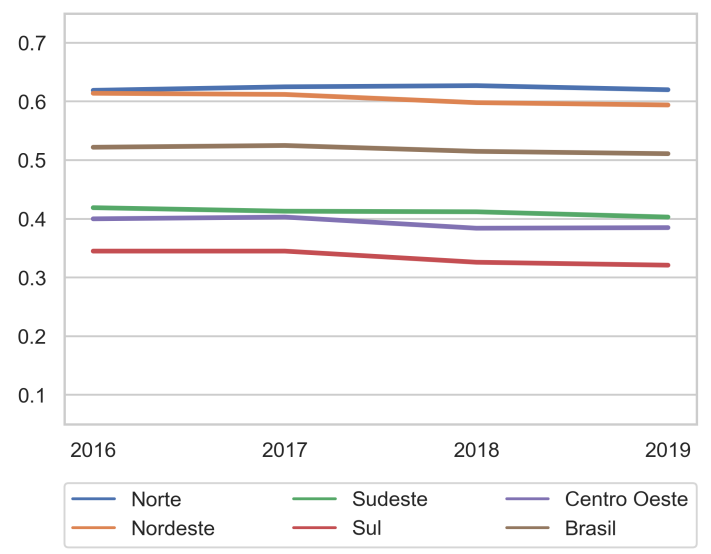

Figura 2. Índice de Pobreza Multidimensional, no meio urbano, por regiões do Brasil, 2005-2019.

(a) 2005-2015

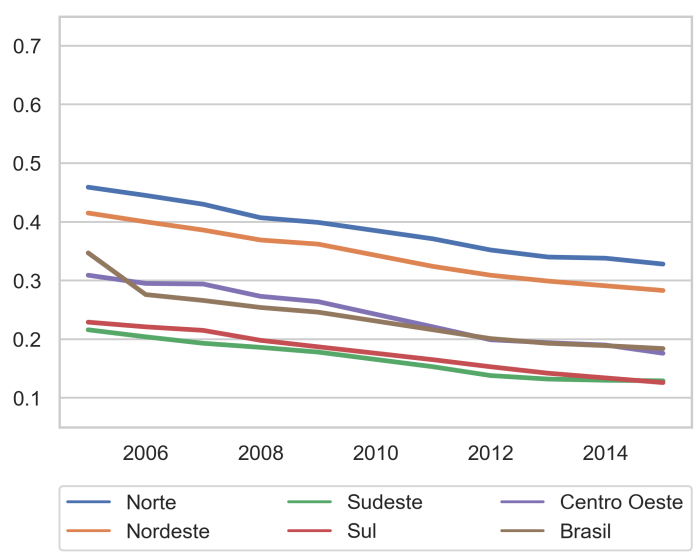

(b) 2016-2019

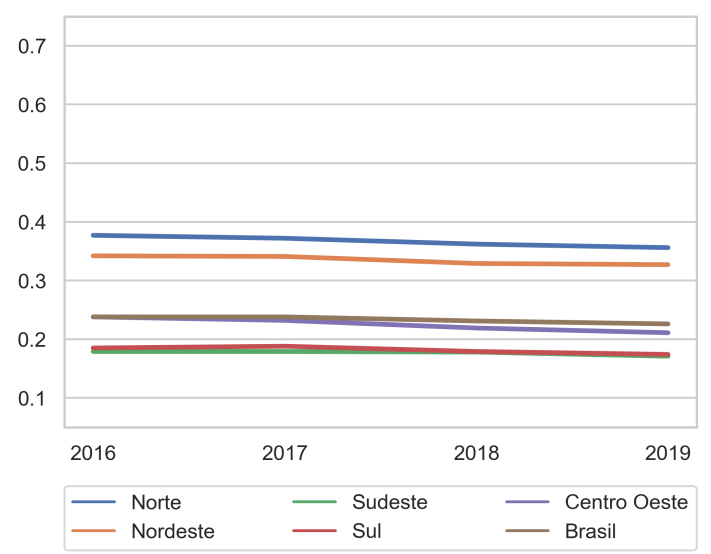

No entanto, dois padrões são observados nos resultados. Primeiramente, a despeito da melhora geral observada nos índices multidimensionais, percebe-se que a 
estrutura da desigualdade regional do Brasil pouco se alterou. Ainda no ano de 2005, tanto a pobreza urbana, quanto a pobreza rural das regiões Norte e Nordeste apresentavam valores bem mais elevados do que a média nacional. Ao longo do recorte temporal, o padrão se manteve em termos regionais, sendo que, em 2015 e em 2019, os niveis de pobreza em ambas as regiões se mantiveram acima da média nacional nos espaços rurais e urbanos. Além disso, observa-se na Tabela 1 que a variação do indice de pobreza é menor para as duas regiões mais pobres do país, em especial, no período de crescimento da economia. Trata-se de um indicativo de que, apesar da queda geral e dos possiveis ganhos sociais gerados pelo crescimento econômico, a desigualdade regional medida pelo IPM aumentou entre as regiões mais pobres e mais ricas do país.

Tabela 1. Variação do Índice de Pobreza Multidimensional, por regiões do Brasil, Urbano e Rural, 2005 a 2015, 2016 a 2019, em termos percentuais (\%)

\begin{tabular}{lcccc}
\hline \multirow{2}{*}{ Regiões } & \multicolumn{2}{c}{ Variação do IPM 2005-2015 } & \multicolumn{2}{l}{ Variação do IPM 2016-2019 } \\
\cline { 2 - 5 } & Rural & Urbano & Rural & Urbano \\
\hline Norte & 13,3 & 39,9 & $-0,1$ & 5,8 \\
Nordeste & 13,9 & 46,6 & 3,3 & 4,5 \\
Sudeste & 31,1 & 67,4 & 3,9 & 4,6 \\
Sul & 56,3 & 81,7 & 7,4 & 6,3 \\
Centro-Oeste & 38,7 & 75,5 & 3,8 & 12,7 \\
Brasil & $\mathbf{1 8 , 7}$ & $\mathbf{8 8 , 5}$ & $\mathbf{2 , 1}$ & $\mathbf{5 , 3}$ \\
\hline \hline
\end{tabular}

Fonte: Elaboração própria a partir dos resultados do IPM.

O segundo padrão refere-se às desigualdades entre os meios urbano e rural. Assim como na comparação entre regiões, percebe-se, primeiramente, que os espaços rurais são mais pobres em termos de privação do que os espaços urbanos, o que é observado ao longo de toda a série histórica analisada. Ao mesmo tempo, em especial até o ano de 2015, as taxas de variação do meio rural foram significativamente mais baixas em relação ao urbano, o que, da mesma forma, mostra que os ganhos do crescimento econômico não foram suficientes para diminuir as disparidades sociais históricas entre campo e cidade. No período mais recente de crise, as variações em ambos os espaços são baixas, mas, ainda assim, no meio rural a variação é menor, como se vê na Tabela 1. Somando essa dinâmica à apresentada anteriormente, é possivel observar que a população que habita em áreas rurais das regiões Norte e Nordeste apresenta o maior índice de privações do país, tendo uma mudança consideravelmente mais baixa no período de crescimento da economia, o que caracteriza a permanência de uma estrutura fortemente desigual. 
Uma outra análise que permite observar a relação entre desigualdade e pobreza, é sobre a trajetória da proporção de pessoas abaixo da linha da pobreza. Para isso, a Tabela 2 apresenta os valores do Headcount $(\mathrm{H})$ para os anos de 2005, 2015, 2016 e 2019, apontando a incidência da pobreza por área e região do país. Cabe destacar ser importante dar ênfase não à intensidade, mas à extensão numérica das privações da população brasileira. Em primeiro lugar, identifica-se um padrão de resultados próximo ao IPM, sendo que a maior incidência de pessoas pobres está nas regiões Norte e Nordeste do país, nos quatro anos considerados. Como na análise do IPM, os resultados do Headcount apresentam importantes informações sobre a estrutura desigual de privações que se perpetuam nas duas primeiras décadas do século XXI. Percebe-se que tanto no meio rural, quanto nas regiões Norte e Nordeste, existe uma parcela muito mais expressiva de população vivendo abaixo da linha da pobreza multidimensional, seguindo o mesmo padrão da pobreza monetária (Dedecca, 2013).

Tabela 2. Pobreza Multidimensional, por região, Brasil, Urbano e Rural, 2005 e 2015, em termos percentuais (\%).

\begin{tabular}{lcccccccc}
\hline \hline \multirow{2}{*}{ Macrorregião } & \multicolumn{5}{c}{ Urbano } \\
\cline { 2 - 8 } Espaço & 2005 & 2015 & 2016 & 2019 & 2005 & 2015 & 2016 & 2019 \\
\hline \multirow{2}{*}{ Norte } & $78,40 \%$ & $62,10 \%$ & $69 \%$ & $66 \%$ & $94,10 \%$ & $92,40 \%$ & $92 \%$ & $93 \%$ \\
Nordeste & $73,00 \%$ & $54,80 \%$ & $63,10 \%$ & $61,70 \%$ & $95,50 \%$ & $92,80 \%$ & $92,70 \%$ & $92,30 \%$ \\
Centro-Oeste & $43 \%$ & $27,30 \%$ & $37,80 \%$ & $36,50 \%$ & $83,30 \%$ & $69,10 \%$ & $72,70 \%$ & $71,30 \%$ \\
Sudeste & $45,20 \%$ & $26,60 \%$ & $38,50 \%$ & $36,90 \%$ & $87,70 \%$ & $63,70 \%$ & $64,10 \%$ & $61,40 \%$ \\
Sul & $58,10 \%$ & $36,30 \%$ & $47,10 \%$ & $43 \%$ & $84,10 \%$ & $66,70 \%$ & $69,60 \%$ & $68 \%$ \\
Brasil & $\mathbf{6 8 , 7 0} \%$ & $\mathbf{3 7 \%}$ & $\mathbf{4 7 \%}$ & $\mathbf{4 5 , 3 0 \%}$ & $\mathbf{9 0} \%$ & $\mathbf{8 2 , 0 0} \%$ & $\mathbf{8 3} \%$ & $\mathbf{8 2 , 7 0 \%}$ \\
\hline \hline
\end{tabular}

Fonte: Elaboração própria a partir dos resultados.

Considerando o período de crescimento da economia brasileira, é perceptível que, além de reduções mais significativas da pobreza em todas as áreas urbanas do país, as áreas rurais das regiões Centro-Oeste, Sul e Sudeste também apresentam este cenário de forma consistente de 2005 a 2015. Contudo, a incidência nas áreas rurais das regiões Norte e Nordeste do país indicam que, mesmo com as políticas sociais do período, boa parte dos domicílios ainda se encontram privados em, no mínimo, cinco dos indicadores considerados no IPM. Assim, a proporção de pessoas abaixo da linha da pobreza multidimensional ainda se manteve persistente, ao longo da década de análise, sendo a diminuição média da parcela da população abaixo da linha da pobreza de apenas dois pontos percentuais.

Já no período de crise, percebe-se que a incidência da pobreza praticamente não sofre alteração, entre 2016 e 2019, culminando em poucos avanços sociais nos espa- 
ços analisados. O que se observa, com base nas dimensões do índice, é que, embora estejam em voga políticas de acesso à renda e educação, o nível elevado de pobreza multidimensional em áreas rurais aponta relação inversa da pobreza com o acesso à infraestrutura básica (energia, água e esgoto). Como apresentam (Medeiros e Oliveira, 2020, p. 16), o efeito positivo do acesso à infraestrutura sobre a redução da pobreza "é potencializado em municípios com maior proporção de indivíduos residentes em zona rural e trabalhando no setor agrícola". Portanto, a importância da compreensão da pobreza, enquanto privações da vida humana, está justamente atrelada aos fatores determinantes da qualidade de vida, plurais e qualitativamente distintos (Nussbaum, 2011). Decorre daí, por sua vez, o fato de que a interpretação do fenômeno esteja inserida em um contexto social particular de cada espaço.

\subsection{Perfil sociodemográfico, regional e espacial da propensão à pobreza no Brasil}

Frente ao propósito de identificar os grupos sociais com maior probabilidade de estar em situação de pobreza de renda e pobreza multidimensional, nos períodos e espaços considerados, segundo características da pobreza em relação à raça, escolaridade, gênero e outros, parte-se aos resultados das regressões logísticas. A Tabela 3 apresenta as estimativas do modelo Logit, cujas variáveis dependentes são pobreza de renda e pobreza multidimensional, para os dados empilhados da PNAD de 2005 a 2015, e da PNAD Contínua de 2016 a 2019, respectivamente. Uma primeira análise a ser feita diz respeito às dummies temporais. Percebe-se que o efeito marginal sobre a probabilidade de ser pobre, em termos de renda, apresenta dinâmicas distintas entre os períodos analisados. Por um lado, no período entre 2005 a 2015, em que os gastos sociais com políticas públicas de transferência de renda tiveram forte expansão, percebe-se que o efeito marginal sobre a probabilidade de ser pobre, em termos de renda, diminui gradativamente, o que indica um número menor de pessoas sujeitas à pobreza por falta de renda. Por outro lado, a inferência para o período entre 2016 e 2019, no qual a austeridade fiscal passou a fazer parte da agenda econômica do país, é de que o efeito marginal sobre a probabilidade de ser pobre, em termos de renda, aumentou neste espaço temporal. Desse modo, é possivel indicar uma relação temporal entre a diminuição dos gastos públicos com políticas de transferência de renda e o aumento da pobreza monetária no país.

É importante destacar esses resultados, pois, sob à luz da Abordagem das Capacidades, o acesso à renda também expande capacidades e funcionamentos, para além da dimensão objetiva, e alcança fatores subjetivos da vida humana, como é o caso da autonomia adquirida pelas mulheres do sertão brasileiro com a chegada do Bolsa Família, como pesquisado por Rego e Pinzani (2014). Aquino e Nascimento (2006) e Nunes et al. (2020) apontam que as políticas de transferência de renda e o crescimento econômico diminuíram a vulnerabilidade da população rural do Nordeste, principalmente, no período da grande seca de 2012 a 2015. Tais estudos mostram que a maior diversidade nas fontes de ocupação e de renda das famílias rurais, marcada pela re- 
Tabela 3. Modelos Logit - Pobreza monetária e pobreza multidimensional, Brasil, 2005 a 2019

\begin{tabular}{|c|c|c|c|c|}
\hline \multirow{3}{*}{ Variáveis de controle } & \multicolumn{2}{|c|}{ Pobreza Monetária } & \multicolumn{2}{|c|}{ Pobreza Multidimensional } \\
\hline & \multicolumn{4}{|c|}{ Efeito marginal } \\
\hline & 2005-2015 & 2016-2019 & $2005-2015$ & 2016-2019 \\
\hline Rural & $0,043^{* * *}$ & $0,041^{* * *}$ & $0,313^{* * *}$ & $0,253 * * *$ \\
\hline Norte & $0,049 * * *$ & $0,046 * * *$ & $0,274^{* * *}$ & $0,252 * * *$ \\
\hline Nordeste & $0,074^{* * *}$ & $0,058^{* * *}$ & $0,218^{* * *}$ & $0,198^{* * *}$ \\
\hline Sul & $-0,010^{* * *}$ & $-0,024^{* * *}$ & $0,034^{* * *}$ & $-0,001^{* * *}$ \\
\hline Centro Oeste & $-0,001^{* * *}$ & $-0,013 * *$ & $0,100^{* * *}$ & $0,064^{* * *}$ \\
\hline Pretos e pardos & $0,022 * * *$ & $0,011^{* * *}$ & $0,068^{* * *}$ & $0,027^{* * *}$ \\
\hline Mulher & $0,024 * * *$ & $0,015^{* * *}$ & $-0,026 * * *$ & $-0,021 * * *$ \\
\hline 0 a 4 anos de estudo & $0,116^{* * *}$ & $0,074^{* * *}$ & $0,290 * * *$ & $0,327^{* * *}$ \\
\hline 5 a 7 anos de estudos & $0,093 * * *$ & $0,064^{* * *}$ & $0,143^{* * *}$ & $0,150 * * *$ \\
\hline 8 a 10 anos de estudos & $0,062 * * *$ & $0,044^{* * *}$ & $0,092 * * *$ & $0,085 * * *$ \\
\hline 14 a 24 anos de idade & $0,186 * * *$ & $0,164 * * *$ & $0,027 * * *$ & $-0,473 * * *$ \\
\hline 25 a 44 anos de idade & $0,162 * * *$ & $0,136^{* * *}$ & $-0,064 * * *$ & $-0,487 * * *$ \\
\hline 45 a 64 anos de idade & $0,107 * * *$ & $0,102 * * *$ & $-0,061 * * *$ & $-0,422 * * *$ \\
\hline Chefe de domicílio & $0,031 * * *$ & $0,028^{* * *}$ & $-0,075^{* * *}$ & $-0,130 * * *$ \\
\hline Ano 2006 & $0,004 * * *$ & & $-0,009 * * *$ & \\
\hline Ano 2007 & $-0,009 * * *$ & & $-0,021 * * *$ & \\
\hline Ano 2008 & $-0,027 * * *$ & & $-0,036 * * *$ & \\
\hline Ano 2009 & $-0,015^{* * *}$ & & $-0,044 * * *$ & \\
\hline Ano 2011 & $-0,040^{* * *}$ & & $-0,083 * * *$ & \\
\hline Ano 2012 & $-0,060^{* * *}$ & & $-0,104 * * *$ & \\
\hline Ano 2013 & $-0,064 * * *$ & & $-0,116 * * *$ & \\
\hline Ano 2014 & $-0,076^{* * *}$ & & $-0,120 * * *$ & \\
\hline Ano 2015 & $-0,070^{* * *}$ & & $-0,126 * * *$ & \\
\hline Ano 2017 & & $0,003^{* * *}$ & & $0,002 *$ \\
\hline Ano 2018 & & $0,006 * * *$ & & $-0,006^{* * *}$ \\
\hline Ano 2019 & & $0,006 * * *$ & & $-0,012^{* * *}$ \\
\hline
\end{tabular}

Fonte: Elaboração própria a partir dos resultados.

Nota: Significância estatística de 5\% (*), 1\% (**) e 0,1\% (***). 
levância crescente de ocupações e rendas não agrícolas, promoveu maior resiliência da população no período de seca e, consequentemente, melhorias nas condições de vida.

No que diz respeito à pobreza multidimensional, percebe-se que as políticas que promovem maior investimento em áreas abordadas pelo IPM, permitem uma mudança social com maior durabilidade no tempo, como é o caso de programas de habitação e educação. Segundo os resultados da regressão, durante todo o período analisado (2005-2019), o efeito marginal da probabilidade de ser pobre em termos multidimensionais diminui. Isso pode ser interpretado pelo fato de que o acesso à casa própria, ao saneamento básico e à educação, em determinado domicílio, é menos suscetível às mudanças macroeconômicas, diferentemente do que acontece com a renda. Certamente, uma família que teve acesso à casa própria, cujos adultos tiveram acesso ao EJA, e que recebiam benefícios do bolsa família, tiveram na transferência de renda a principal perda em termos de capacidades, dentro do atual contexto de crise que vigora desde 2016. Desse modo, os resultados temporais indicam que políticas voltadas para o combate de um conjunto de privações de grupos vulneráveis, surtem efeito para o médio e longo prazo.

Uma segunda análise diz respeito ao perfil sociodemográfico dos grupos mais propensos à situação de pobreza. O destaque a ser dado diz respeito às variáveis de controle de educação e cor. Em ambas abordagens (monetária e multidimensional), observa-se que a probabilidade de estar abaixo da linha da pobreza é maior para os grupos menos escolarizados, pretos e pardos, em ambas as séries temporais. Destacase também que esses grupos apresentam propensão ainda maior à pobreza, quando se trata da abordagem multidimensional. Isso indica privações a esses grupos que vão para além da renda, um indicativo de que são os grupos que mais sofrem com a falta de saneamento, condições precárias da habitação e grandes obstáculos no acesso à educação. Cenário esse corroborado pela avaliação feita pela Síntese de Indicadores Sociais da Análise das Condições de Vida da População Brasileira, feita pelo IBGE (2018), de que a cor e a escolaridade ainda são determinantes estruturais da pobreza multidimensional.

O terceiro ponto a ser ressaltado, a partir dos resultados da regressão, é sobre o comportamento da pobreza segundo categorias espaciais e regionais. Ao abordar a pobreza, segundo essas variáveis de controle, dois pontos merecem destaques: i) o efeito marginal da probabilidade de pobreza multidimensional é significativamente superior ao da pobreza monetária, quando se considera as variáveis de controle de espaço e região; ii) as estimativas corroboram os resultados do IPM, pois o efeito marginal da probabilidade de pobreza multidimensional é superior para as populações rurais e das regiões Norte e Nordeste, havendo também um efeito superior para essas populações, no que diz respeito à abordagem da pobreza de renda.

No que se refere às dummies de regiões, há considerável peso regional na probabilidade de pobreza. Avaliando-se a probabilidade de estar abaixo da linha da pobreza 
de renda, é perceptível que as populações das regiões Norte e Nordeste apresentam maiores chances em relação às populações da região Sudeste, seja no período de crescimento da economia, ou no período de recessão econômica. Assim, mesmo com os importantes avanços sociais que permitiram diminuir a pobreza de renda em áreas pobres localizadas nas regiões Norte e Nordeste (Buainain et al., 2013; Rego e Pinzani, 2014), a população dessas regiões ainda se encontra mais suscetível à condição de pobreza que a população de outras regiões do país.

No que diz respeito à probabilidade de o indivíduo ser pobre, em termos multidimensionais, o efeito marginal é significativamente maior. Se em termos de renda, para as regiões Norte e Nordeste, o efeito marginal da probabilidade de ser pobre em relação à região Sudeste é maior em 0,049 e 0,074 de 2005 a 2015, e 0,046 e 0,058 de 2016 a 2019, em termos multidimensionais, o efeito é de 0,274 e 0,218 (2005-2015), e 0,252 e 0,198 (2016-2019). Essa característica se repete, quando inserida a variável de controle meio rural e urbano. Assim como na dimensão regional, o efeito marginal de probabilidade de ser pobre é maior para o indivíduo que vive no meio rural, em especial, quando se considera a pobreza em termos multidimensionais. Considerando o período de 2005 a 2015, o efeito marginal da probabilidade de ser pobre, em termos de renda, para o indivíduo do meio rural, em relação ao indivíduo urbano é de 0,043, enquanto, de 2016 a 2019, esse valor é de 0,041. Já em relação à pobreza multidimensional, a propensão de estar na situação de pobreza é significativamente maior para o indivíduo do meio rural.

A partir dos dados de 2005 a 2015, o efeito marginal da probabilidade de ser pobre, em termos multidimensionais, é de 0,313, ao passo que, no período de 2016 a 2019, esse valor é de 0,253. Somando-se aos apontamentos obtidos com as dummies temporais, observa-se que, embora se verifique a diminuição do efeito marginal da probabilidade de ser pobre em termos multidimensionais ao longo da série analisada, alguns grupos sociais se encontram em situação de vulnerabilidade muito superior. Nesse sentido, os resultados da regressão Logit vão ao encontro dos resultados do Índice de Pobreza Multidimensional. Isso evidencia que, quando observadas pelas privações não monetárias que atestam sobre as condições de vida das pessoas, a situação de pobreza é ainda maior e mais desigual entre grupos da sociedade, diferenciados por escolaridade, cor, local e região de habitação.

As inferências aqui obtidas se assemelham a padrões observados em estudos recentes acerca do crescimento econômico e das políticas de transferência de renda serem eficazes quanto a gerar maior resiliência às populações mais vulneráveis, como no caso da população rural da região Nordeste (Aquino e Nascimento, 2006; Nunes et al., 2020). Todavia, tais estratégias não são eficientes quanto aos problemas associados à infraestrutura, traços marcantes do grande gargalo desses espaços (Medeiros e Oliveira, 2020) e das áreas urbanas de pequenas e médias cidades (D’Ottaviano e Pasternak, 2015). Nesse sentido, para além do acesso à renda, a água, a energia elétrica, o transporte e a moradia de qualidade, continuam sendo graves privações da 
sociedade brasileira, inibidoras da expansão das capacidades humanas e do potencial de desenvolvimento do país.

Desse modo, as diferenças observadas entre a probabilidade de pobreza monetária e pobreza multidimensional mostram uma mudança conjuntural da pobreza na década observada, porém, apontam a permanência estrutural do fenômeno social no Brasil. Os resultados refletem a tendência estrutural presente no processo histórico de formação da sociedade brasileira, o que indica a continuidade de estruturas desiguais materializadas no espaço. Como afirma (Dedecca, 2013, p. 20), a presença significativa da pobreza rural no Nordeste pode ser "tomada como expressão do desenvolvimento regional desequilibrado do período de 1930 e 1980, qual foi reiterado, nas últimas décadas, pela situação de crise gerada pelas transformações produtivas recentes ocorridas no campo".

Nesse sentido, esses resultados mostram que, não obstante a estrutura produtiva da economia brasileira tenha se desconcentrado regionalmente nas primeiras décadas do século XXI (Monteiro Neto, 2014), ainda permanece uma rígida estrutura desigual no âmbito social. Isso vai ao encontro do pensamento de que as desigualdades brasileiras não são mais apenas uma "questão regional”, ou seja, particular de cada uma, mas sim uma "questão nacional" (Araújo, 2006), estando as questões sociais dessas regiões também interligadas. É visivel que as desigualdades regionais, sobretudo, entre áreas rurais e urbanas, persistem e, dentro de um circuito sem a presença efetiva do Estado, tendem a apresentar um círculo vicioso, no qual as regiões e áreas pobres se beneficiem menos do crescimento econômico nacional em decorrência do movimento de acumulação do capital e consequente enriquecimento de áreas e regiões ricas (Myrdal, 1960).

Por fim, denota-se que ambas as estratégias empíricas adotadas no estudo apontam a necessidade de compreender a pobreza rural a partir de uma ótica multidimensional, na linha do que defende o Instituto Interamericano de Cooperação para a Agricultura (IICA), ao organizar importantes estudos em torno da compreensão e do enfretamento da pobreza no campo (IICA, 2011, 2013), atentando-se à necessidade de compreender e enfrentar o problema a partir de uma perspectiva ampla e multidimensional. Trabalhos recentes de importantes cientistas do meio rural brasileiro, como o de Wanderley (2014), também apontam para o fato de que a presença de pobres no meio rural ainda é significativamente elevada, sendo necessário incorporar nos estudos de pobreza do campo as verdadeiras privações incidentes sobre a população, associadas a questões de infraestrutura, disponibilidade de recursos básicos e acesso à serviços públicos necessários.

\section{Considerações finais}

Algumas questões relevantes emergem da proposta de analisar as mudanças da pobreza multidimensional no Brasil nas primeiras décadas do século XXI. O Índice 
de Pobreza Multidimensional aponta queda em todas as macrorregiões e nas áreas rurais e urbanas do país entre 2005 e 2019, um indicativo da eficácia direta e indireta das políticas de crescimento econômico e de redistribuição de renda adotadas no período sobre uma série de dimensões da pobreza. Todavia, a variação do IPM foi menor nas áreas de nível mais elevado de pobreza, quais sejam o meio rural do Norte e do Nordeste. Além disso, a proporção de pessoas abaixo da linha da pobreza multidimensional nessas áreas também continuou, praticamente, inalterada no período considerado, com porcentagem elevada e acima de $90 \%$.

Também se confirma, pela abordagem multivariada via modelo Logit, os resultados mostrados pelo Índice de Pobreza sobre as diferenças acentuadas entre áreas rurais e urbanas, regiões e grupos sociais no Brasil. As inferências de probabilidade da pobreza, do ponto de vista da renda e do ponto de vista multidimensional, indicam que, no período de 2005 a 2019, os brasileiros pretos e pardos, menos escolarizados, moradores das áreas rurais e das regiões Norte e Nordeste estiveram mais propensos à situação de pobreza. Soma-se a isso o fato de que, no período que contempla a crise econômica brasileira, o efeito marginal da probabilidade de pobreza monetária torna-se positivo, depois de quase dez anos de queda.

Além disso, a probabilidade de pobreza multidimensional para a população rural e das regiões Norte e Nordeste é significativamente maior em relação às populações urbanas e das outras regiões do Brasil. Desse modo, para além da evidência de que a pobreza alcançou níveis mais baixos ao longo dos anos analisados, percebe-se ainda uma estrutura desigual entre regiões, entre os espaços rural e urbano e entre grupos sociais mais vulneráveis da sociedade, como pretos e pardos, e menos escolarizados. Trata-se de um cenário no qual, a despeito dos ganhos sociais resultantes de políticas no período considerado, a desigualdade marcada pela pobreza ainda está fortemente presente no território brasileiro.

Tais contextos permitem constatar que a pobreza multidimensional continua persistente e, de certa forma, mais intensa, nas áreas com menor dinamismo econômico, em especial, atingindo a população das áreas rurais do Norte e Nordeste brasileiro. Mesmo ocorrendo decréscimo na pobreza multidimensional no período analisado, observa-se que, nesses espaços, o avanço foi bem menos expressivo. Nesse sentido, ainda que a diminuição da pobreza de renda tenha sido extremamente importante para a expansão de uma série de capacidades humanas, é visivel que a população brasileira ainda sofre de privações básicas, como acesso à água potável e saneamento básico, sendo isso preponderante para avaliação das condições de vida das pessoas.

Desse modo, faz-se importante mostrar que a pobreza e as desigualdades entre grupos da sociedade brasileira ainda são alarmantes. De forma agravante, o avanço dos problemas sanitários, sociais, econômicos e políticos tendem a atingir, sobretudo, os segmentos sociais historicamente mais vulneráveis econômica e socialmente. No contexto de pandemia, que vigora desde 2020, outras análises devem surgir para compreender a dinâmica da pobreza em um contexto de agravamento da crise econômica 
e fortalecimento de inúmeras privações que cercam as populações mais vulneráveis do país. Assim, os dados da PNAD Contínua, do período pós-pandemia, e também do Censo Demográfico, são fundamentais para orientar futuros estudos sobre os impactos da pandemia na pobreza, tanto em termos de renda quanto em termos multidimensionais.

\section{Referências}

Alkire, S. e Foster, J. (2008). Counting and multidimensional poverty measurement. Oxford Poverty Human Development Initiative, Working Paper n. 7.

Alkire, S., Roche, J. M., Ballon, P., Foster, J., Santos, M. E., e Seth, S. (2015). Multidimensional poverty measurement and analysis. Oxford University Press, USA.

Aquino, J. R. d. e Nascimento, C. A. d. (2006). A grande seca e as fontes de ocupação e renda das famílias rurais no nordeste do Brasil (2011-2015). Revista Econômica do Nordeste, 51(2):81-97.

Araújo, T. B. (2006). Revisitando a questão regional. Cadernos do Desenvolvimento, $1(1): 59-76$.

Bagolin, I. P., Souza, O. T. d., e Comim, F. V. (2012). Gênero e pobreza multidimensional no município de porto alegre, rio grande do sul. Economia e Sociedade, 21:387-408.

Bebbington, A. (1999). Capitals and capabilities: A framework for analysing peasant viability, rural livelihoods and poverty in the Andes. IIED London.

Buainain, A. M., Dedecca, C. S., e Neder, H. D. (2013). Características regionais da pobreza rural no brasil: algumas implicações para políticas públicas. In: Miranda, C. e Tiburcio, B., editores, A nova cara da pobreza rural: desenvolvimento e a questão regional, Página 57-110. IICA, Brasília.

Cardoso, D. (2016). Capital e trabalho no Brasil do século XXI: o impacto de politicas de transferência e de tributação sobre desigualdade, consumo e estrutura produtiva. Tese de Doutorado, Universidade Federal de Minas Gerais, Centro de Desenvolvimento e Planejamento Regional, Belo Horizonte.

Chambers, R. e Conway, G. (1991). Sustainable rural livelihoods: practical concepts for the 21st century. Texto para discussão, IDS Discussion Paper 296.

Codes, A. (2008). A trajetória do pensamento científico sobre pobreza: em direção a uma visão complexa. Texto para Discussão 1332, Instituto de Pesquisa Econômica Aplicada (Ipea), Brasília.

Comim, F., Bagolin, I. P., Avila, R., Porto Júnior, S., e Picolotto, V. (2006). Pobreza: da insuficiência de renda à privação das capacitações. uma aplicação para a cidade 
de porto alegre através de um indicador multidimensional. Texto para discussão, Projeto de Pesquisa: Pobreza Multidimensional em Porto Alegre.

Dedecca, C. S. (2013). Contribuições para a agenda da política de combate à pobreza rural. In: Miranda, C. e Tiburcio, B., editores, A nova cara da pobreza rural: desenvolvimento e a questão regional, Página 19-32. IICA, Brasília.

D’Ottaviano, C. e Pasternak, S. (2015). Políticas recentes de melhorias urbanas: municípios pequenos e médios e favelas. Revista Brasileira de Estudos Urbanos e Regionais (RBEUR), 17(1):75-88.

Gujarati, D. N. e Porter, D. C. (2008). Econometria básica. The McGraw-Hill Companies, Inc., New York, EUA.

IBGE (2017). Classificação e caracterização dos espaços rurais e urbanos no Brasil. Instituto Brasileiro de Geografia e Estatística.

IBGE (2018). Sintese de Indicadores Sociais: Uma Análise das Condições de Vida da População Brasileira. Instituto Brasileiro de Geografia e Estatística.

IICA (2011). Pobreza rural: concepções, determinantes e proposições para a construção de uma agenda de políticas públicas. Instituto Interamericano de Cooperação para a Agricultura (IICA).

IICA (2013). A nova cara da pobreza rural: desenvolvimento e a questão regional. Instituto Interamericano de Cooperação para a Agricultura (IICA).

Martins, J. S. (2010). O cativeiro da terra. Editora Contexto, 9. ed, São Paulo.

Medeiros, V. e Oliveira, A. M. H. C. d. (2020). O acesso à infraestrutura e a pobreza no brasil: uma investigação empírica. Revista de Economia e Sociologia Rural, 58.

Monteiro Neto, A. (2014). Desigualdades regionais no brasil: caracterísiticas e tendências recentes. Boletim regional, urbano e ambiental (IPEA), 9.

Myrdal, G. (1960). Teoria econômica e regiões subdesenvolvidas. Editora Saga, Rio de Janeiro.

Nunes, E. M., Silva, P. S. G. d., Silva, M. R. F. d., e Sá, V. C. d. (2020). O índice de condições de vida (icv) em territórios rurais do nordeste: evidências para os territórios açu-mossoró e sertão do apodi, no rio grande do nortel. Revista de Economia e Sociologia Rural, 58.

Nussbaum, M. e Sen, A. (1996). La calidad de vida. Página 588. Fondo de Cultura Económica. Edic. 1era., México DF, México.

Nussbaum, M. C. (1987). Nature, function and capability: Aristotle on political distribution. Texto para discussão, Wider Working Papers, WP31. 
Nussbaum, M. C. (2000). Women and Human Development. Number 3. Cambridge University Press, New York.

Nussbaum, M. C. (2011). Creating capabilities. Harvard University Press.

Osório, R. (2015). Desigualdade e pobreza. In: Instituto de Pesquisa Econômica Aplicada, editor, PNAD 2014 - breves análises, Nota Técnica nํ22. IPEA, Brasília.

Pinheiro, M. (2012). As liberdades humanas como bases do desenvolvimento: uma análise conceitual da abordagem das capacidades humanas de amartya sen. Texto para discussão, Texto para discussão no 1794/IPEA. Rio de Janeiro.

PNUD (2019). Além dos rendimento, além das médias, além do presente: as desigualdades no desenvolvimento humano no século XXI. Programa das Nações Unidas para o Desenvolvimento (PNUD). Relatório de Desenvolvimento Humano, UN Plaza, New York.

Rego, W. e Pinzani, A. (2014). Vozes do Bolsa Família: autonomia, dinheiro e cidadania. Editora Unesp, São Paulo, 2 edition.

Ribeiro, E. (1997). As estradas da vida: história da terra, da fazenda e do trabalho no Mucuri e Jequitinhonha. Tese de Doutorado, IFCH/Unicamp, Campinas.

Robeyns, I. (2005a). The capability approach: a theoretical survey. Journal of human development, 6(1):93-117.

Robeyns, I. (2005b). Selecting capabilities for quality of life measurement. Social indicators research, 74(1):191-215.

Schneider, S. e Freitas, T. D. (2013). Gualidade de vida, diversificação e desenvolvimento: referências práticas para análise do bem-estar no meio rural. Revista Olhares Sociais, 2(1):121-142.

Sen, A. (1986). Food, economics and entitlements. Texto para discussão, Wider Working Papers, wp. 1.

Sen, A. (1993). Capability and well-being. In: Nussbaum, M. e Sen, A., editores, The Quality of Life. Clarendon Press, Oxford.

Sen, A. (1999). Sobre ética e economia. Companhia das Letras, São Paulo.

Sen, A. (2000). Desenvolvimento como liberdade. Companhia das Letras, São Paulo.

Sen, A. (2001). Desigualdade reexaminada. Record, Rio de Janeiro.

Sen, A. (2004). Elements of a theory of human rights. Philosophy \& public affairs, 32(4):315-356.

Serra, A. (2017). Pobreza multidimensional no Brasil rural e urbano. Tese de Doutorado, Programa de Pós-Graduação em Desenvolvimento Econômico (UNICAMP), Campinas. 
Silva, J. (1980). O que é questão agrária. Editora Brasiliense, São Paulo.

Vieira, C., Kuhn, D., e Marin, S. (2014). Método Alkire Foster: Uma aplicação para medição da pobreza multidimensional no rio grande do sul (2000-2010). Revista de Planejamento e Políticas Públicas (IPEA), (48):263-295.

Wanderley, M. d. N. B. (2014). O campesinato brasileiro: uma história de resistência. Revista de Estudos Rurais, 52, s. 1:25-44.

Wooldridge, J. (2010). Introdução à Econometria: Uma abordagem Moderna. Cengage Learning, São Paulo.

Este artigo está licenciado com uma CC BY 4.0 license. 


\section{Anexos}

Tabela A.1. Índice de Pobreza Multidimensional (IPM), por região, rural, 2005 a 2015

\begin{tabular}{lcccccccccc}
\hline \hline & \multicolumn{10}{c}{ Ano } \\
\cline { 2 - 11 } Região & 2005 & 2006 & 2007 & 2008 & 2009 & 2011 & 2012 & 2013 & 2014 & 2015 \\
\hline Norte & 0,670 & 0,654 & 0,632 & 0,611 & 0,602 & 0,636 & 0,627 & 0,609 & 0,593 & 0,591 \\
Nordeste & 0,670 & 0,665 & 0,655 & 0,639 & 0,630 & 0,617 & 0,608 & 0,599 & 0,592 & 0,588 \\
Sudeste & 0,505 & 0,484 & 0,465 & 0,442 & 0,427 & 0,437 & 0,407 & 0,392 & 0,378 & 0,385 \\
Sul & 0,519 & 0,498 & 0,482 & 0,467 & 0,449 & 0,426 & 0,390 & 0,371 & 0,360 & 0,332 \\
Centro Oeste & 0,501 & 0,502 & 0,476 & 0,480 & 0,462 & 0,412 & 0,409 & 0,387 & 0,370 & 0,361 \\
Brasil & 0,589 & 0,577 & 0,563 & 0,547 & 0,537 & 0,538 & 0,522 & 0,509 & 0,500 & 0,496 \\
\hline \hline
\end{tabular}

Fonte: Elaboração própria a partir dos resultados.

Tabela A.2. Índice de Pobreza Multidimensional (IPM), por região, urbano, 2005 a 2015

\begin{tabular}{lcccccccccc}
\hline \hline & \multicolumn{10}{c}{ Ano } \\
\cline { 2 - 11 } Região & 2005 & 2006 & 2007 & 2008 & 2009 & 2011 & 2012 & 2013 & 2014 & 2015 \\
\hline Norte & 0,459 & 0,445 & 0,430 & 0,407 & 0,399 & 0,371 & 0,352 & 0,340 & 0,338 & 0,328 \\
Nordeste & 0,415 & 0,400 & 0,386 & 0,369 & 0,362 & 0,324 & 0,309 & 0,299 & 0,291 & 0,283 \\
Sudeste & 0,216 & 0,204 & 0,193 & 0,186 & 0,178 & 0,153 & 0,138 & 0,132 & 0,130 & 0,129 \\
Sul & 0,229 & 0,221 & 0,215 & 0,198 & 0,187 & 0,165 & 0,153 & 0,142 & 0,134 & 0,126 \\
Centro Oeste & 0,309 & 0,295 & 0,294 & 0,273 & 0,264 & 0,221 & 0,199 & 0,194 & 0,190 & 0,176 \\
Brasil & 0,347 & 0,276 & 0,266 & 0,254 & 0,246 & 0,216 & 0,201 & 0,193 & 0,189 & 0,184 \\
\hline \hline
\end{tabular}

Fonte: Elaboração própria a partir dos resultados.

Tabela A.3. Índice de Pobreza Multidimensional (IPM), por região, rural e urbano, 2016 a 2019

\begin{tabular}{|c|c|c|c|c|c|c|c|c|}
\hline \multirow[b]{2}{*}{ Região } & \multicolumn{4}{|c|}{ Rural } & \multicolumn{4}{|c|}{ Urbano } \\
\hline & 2016 & 2017 & 2018 & 2019 & 2016 & 2017 & 2018 & 2019 \\
\hline Norte & 0,619 & 0,625 & 0,627 & 0,620 & 0,377 & 0,372 & 0,362 & 0,356 \\
\hline Nordeste & 0,614 & 0,612 & 0,598 & 0,594 & 0,342 & 0,341 & 0,329 & 0,327 \\
\hline Sudeste & 0,419 & 0,413 & 0,412 & 0,403 & 0,179 & 0,179 & 0,178 & 0,171 \\
\hline Sul & 0,345 & 0,345 & 0,326 & 0,321 & 0,185 & 0,188 & 0,179 & 0,174 \\
\hline Centro Oeste & 0,400 & 0,403 & 0,384 & 0,385 & 0,238 & 0,232 & 0,219 & 0,211 \\
\hline Brasil & 0,522 & 0,525 & 0,515 & 0,511 & 0,238 & 0,238 & 0,231 & 0,226 \\
\hline
\end{tabular}

Fonte: Elaboração própria a partir dos resultados. 